\title{
Network effects of frequency dependent phase response curves
}

\author{
Chris Fink ${ }^{1}$, Victoria Booth ${ }^{2,3^{*}}$, Michal Zochowski ${ }^{3}$ \\ From Nineteenth Annual Computational Neuroscience Meeting: CNS*2010 \\ San Antonio, TX, USA. 24-30 July 2010
}

Phase response curves (PRCs) are experimentally obtainable measures of the effects of small perturbations to a neuron on the timing of its firing. The PRC assumes that the neuron is repetitively firing at a constant frequency and that the perturbation is small relative to the period of the oscillation. Theoretical and simulation results have shown that neurons whose PRCs show a region of phase delay for early stimulus phases and a region of phase advance for late stimulus phases, called Type II PRCs, tend to synchronize more readily when synaptically coupled than neurons whose PRCs show only phase advances at all stimulus phases, called Type I PRCs. It has not been determined if PRC-induced properties of synchronization continue to hold in networks where the neurons are not intrinsically oscillatory, the synaptic coupling is not uniform, and neurons receive multiple inputs during each spike cycle. To investigate the influence of the neuronal PRC on network dynamics, we consider the effects upon synchronization of changes in the amplitude of the PRC that occur with changes in intrinsic firing frequency of neurons in large, noisy, non-uniform networks. We show that as the average network firing frequency increases, networks consisting of neurons with Type I PRCs show an increase in synchronization over large ranges of synaptic connectivity parameters. This is expected, as an increase in average synaptic current leads to greater effective coupling among neurons. In contrast, networks of neurons with Type II PRCs show a decrease in synchronization as frequency increases, implicating the influence of frequencydependent changes in the PRC upon network synchronization.

* Correspondence: vbooth@umich.edu

${ }^{2}$ Mathematics, University of Michigan, Ann Arbor, MI 48104, USA

\section{Author details}

Physics, University of Michigan, Ann Arbor, MI 48104, USA. ${ }^{2}$ Mathematics, University of Michigan, Ann Arbor, MI 48104, USA. ${ }^{3}$ Anesthesiology, University of Michigan, Ann Arbor, Ml 48104, USA.

Published: 20 July 2010

doi:10.1186/1471-2202-11-S1-P40

Cite this article as: Fink et al:: Network effects of frequency dependent phase response curves. BMC Neuroscience 2010 11(Suppl 1):P40.
Submit your next manuscript to BioMed Central and take full advantage of:

- Convenient online submission

- Thorough peer review

- No space constraints or color figure charges

- Immediate publication on acceptance

- Inclusion in PubMed, CAS, Scopus and Google Scholar

- Research which is freely available for redistribution

Submit your manuscript at www.biomedcentral.com/submit
C Biomed Central 